\title{
TECHNOLOGY AND THE YOUTH OF THE GENERATION Z A CASE STUDY OF COLLEGE STUDENTS AT A LAW SCHOOL
}

\author{
Sónia Rolland Sobral ${ }^{1}$ \\ ${ }^{1}$ DEGI, Universidade Portucalense, Oporto, Portugal
}

\begin{abstract}
This article belongs to a study to portray the university students of the generation Z, particularly those who did not follow technological courses. The widespread idea que these young people are experts in technology may not be correct. Digital natives live surrounded by technology, use technology to communicate and to have fun, but many of them show a lack of knowledge of some tools, including MsOffice. These tools prove to be essential during their academic life and their future working life. This article presents results from two surveys: the initial investigation on computer equipment possessed, social networks used, kind of applications access, knowledge of MsOffice tools; the second survey on MsOffice tools, was completed at the end of the course, in which were not taught but were necessary for the final work preparation and presentation. In Portugal there is a curriculum in secondary education but not all students were included. What we want is to know the knowledge that students have when they go to university and the knowledge they need to have to go to the labor market.
\end{abstract}

Keywords - technology; curriculum; digital generations; higher education

\section{THE STUDY/PROBLEM}

The digital natives [1] live surrounded by technology: they use technology to communicate and to have fun. They were born in a time where the internet already existed, for them it's usual to browse the web, it's a part of their life. They're element of the generation Z [2], which is a designation used to address young people born in the 90's, who "zap" between various devices and electronics apps. The letter Z comes from the term "to zap", the action to constantly change the TV channel, much like this generation is in life: with various tasks at the same time and always changing interests. Many studies have been made and they all point to a large use of digital devices, namely the cell phone, the laptops, the iPads, and much like a series of ultra-sophisticated gaming consoles. Social networks are used by all young people: Facebook, Instagram, Snapchat and a series of other apps are used by young people all over the world. Actually this generation is really different from former generations, which, by being digital immigrants, don't use technology so innately. But the widespread idea that 18-year-olds are experts in technology might not be the most correct: what if we talk about some "serious work"? Would a college freshman know how to use MsWord correctly? I'm not talking about creating a document, changing the font, writing, recording and printing. Any child is almost born knowing how to use a text processer. I'm talking about using well, using the functionalities that MsWord provides. Would a freshman know how to use functionalities such as the creation of an automatic index, a cross reference, captioning a figure or inserting a new font for a quote? Would the freshman know what slide master of MsPowerPoint is or does he alter the configuration of each one of the slides whenever he does school presentations? Is MsExcel a useful tool or just an app where you put numbers, much like in battleship? I have 22 years of experience in college education and in the area of informatics. Many times I lection other courses, namely Law. By what I have been seeing, many students get to college with very little competencies in terms of MsOffice, a tool which they'll have to use in the following years. The advantage is that after taught they'll learn fast because they have easiness with the use of technology. The disadvantage is that if they don't know how to properly use that functionality, they'll probably try to do it wrongly: "zapping" between the various possibilities, not doing correctly. In the last school year I teach technological courses (memories, emerging technologies, disruptive and so on) on a curricular unit to first year students of law. In the beginning I asked them to fill an inquiry about what computer hardware they possessed, which social networks they used, what type of apps they accessed, if they knew how to use some functionalities of MsOffice. It was a way to picture the students. One of this discipline's evaluation items consisted in a work about an emerging technology of their choosing. The work for evaluation consisted in a document in MsWord and the respective presentation in MsPowerPoint or Prezi. There was a guide that they had to follow, describing, namely, the elements which had to appear in the cover, the bibliographical references, the various indexes, information that all images had to be captioned and labeled, just like other requisites. The students sent in the work through MOODLE and did the presentation in the due 
date. In that day, and after the presentation and discussion of the work, they were asked to answer an inquiry. 56 students answered. Purposely, the answers were only given after the presentation of the work, since that, in that phase, they had already discovered their difficulties. Also because the work featured many requisites that many of them didn't do automatically. And in the discussion I insisted in telling them that. In Portugal there's a curriculum in high school but not all students were contemplated. And, many times, that which is taught in those high school disciplines is linked with internet, blogs or sites. It looks like the tools of MsOffice are a poor relative of technology, when in truth they are powerful means of work (and not only!). This document shows the results of that inquiry and does some recommendations about which are the competences that a student should have before he gets to College, or, in case that that's not possible, what are the competences that a College should give to the students which sign up for the first time.

\section{THE INQUIRIES}

Both inquiries were answered with Google Drive, being the link put on the MOODLE platform which was available for students which that these students were motivated to work with. The inquiries were anonymous for obvious reasons, however it was asked that the student number was filled to verify if no student did more than one inquiry and to join with the initial inquiry where were there were other information, which could be useful. To the initial inquiry answered 217 students from various courses. However we'll only take away the students in Law: 117 students. 4 answers of 26-years-olds were taken away, because they weren't classified as Generation Z anymore. In this first inquiry it was asked: a) Personal information: Student number, Birth year, Gender and Course. b) Relation with technology (1nothing to 5-much): Fondness for technology? Interest for technology? Technological dexterity? And Motivation for the learning of ITs. c) If they had an account on Facebook, Gmail, YouTube, Instagram, Snapchat, Twitter, Linkedln, Google +, Blogs/WordPress. d) Uses regularly: Digital libraries, Wikipedia, Google. e) Usually the web servers for: Social networks, Newspapers, Digital libraries, Games, E-mail. f) Has 3G, 4G, PS4 (or similar), Laptop, Tablet, Smartphone. g) On Word knows how to do: Sections, Chapter index, Figures/Tables index..., Manage bibliographical references, Different headers/footer, Cross-reference. h) On Excel knows how to do: Insert formulas/functions, using filters, creating graphics, doing ordinations. I) On PowerPoint knows how to do: Temporizations, Animations, Using the slide master, Transitions. j) Had some informatics discipline in high school. If yes: which disciplines did you have? In which grades? If yes: were those disciplines useful? How? To the final inquiry responded 56 students, all from the course of Law, 3 answers were outed by three students who were born before the 90's since we pretended to study the generation born in that decade. In this second inquiry it was asked: a) Personal information: Student number, Birth Date, Gender. b) On Word knows how to do (1-Nothing to 4-Much): Different headers / footers, number of different pages per section, Chapter index, Captioning figures / tables..., Figures/ Tables index..., Manage bibliographical references, Cross-reference. c) On Excel knows how to do (Yes/No): Insert formulas/functions, Use filters, Create graphics, doing ordinations. d) On PowerPoint knows how to do (Yes/No): Temporizations, Animations, Using slide master, Transitions. e) Do you think you should have lessons about Word /Prezi and other tools in the beginning of the semester? If yes answer why?

\section{INITIAL INQUIRY}

This curricular unit had 553 students signed, from which 217 responded to the initial inquiry. On this article we only consider students from the course of Law: 137 were signed, from which 117 answered to the inquiry (85.4\%). How our study pretends to address the students born in the 90's (Generation Z), we take away four: born in 1971, 1981, 1985 and 1989. By which we stand with 113 students in this first inquiry. By those means: the age average was 20, like students born in 1996 . Just $22.12 \%$ of the students who answered the inquiry were masculine.

TABLE 1. BIRTH YEAR, INQUIRY 1.

\begin{tabular}{|c|c|c|}
\hline Birth year & № & $\%$ \\
\hline 1992 & 1 & $0,88 \%$ \\
\hline 1993 & 14 & $12,39 \%$ \\
\hline 1994 & 18 & $15,93 \%$ \\
\hline 1995 & 32 & $28,32 \%$ \\
\hline 1996 & 46 & $40,71 \%$ \\
\hline 1997 & 2 & $1,77 \%$ \\
\hline
\end{tabular}


TABLE 2. GENDER, INQUIRY 1.

\begin{tabular}{|c|c|c|}
\hline Gender & № & $\%$ \\
\hline Feminine & 88 & $77,88 \%$ \\
\hline Masculine & 25 & $22,12 \%$ \\
\hline
\end{tabular}

When asked to classify by fondness and interest for technology, along with technological dexterity, being the scale from 1 (nothing) to 5 (much), ten students answered to the three items with a 5 , none of them answering to the same three items. The average was close to 4.

TABLE 3. FONDNESS, INTEREST ANDTECHNOLOGICAL DEXTERITY, INQUIRY 1.

\begin{tabular}{|c|c|c|c|c|c|c|}
\hline & 1 & 2 & 3 & 4 & 5 & Average \\
\hline Fondness for technology? & 1 & 4 & 17 & 46 & 43 & 4,14 \\
\hline Interest for technology? & 0 & 5 & 25 & 46 & 35 & 4,00 \\
\hline Technological dexterity? & 1 & 10 & 39 & 47 & 14 & 3,57 \\
\hline
\end{tabular}

Most students possess an account on Facebook (87\%), no Gmail (83\%), no YouTube (78\%), Instagram (65\%), and SnapChat (62\%). Just some have an account on Twitter (19\%), Linkedln (9\%), Google + $(49 \%)$, and Blogs/WordPress (21\%). Two students said that they had an account on the five sites in question.

\section{TABLE 4. ACCOUNTS, INQUIRY 1}

\begin{tabular}{|c|c|c|}
\hline Has account: & Yes & No \\
\hline Facebook & 98 & 15 \\
\hline Gmail & 94 & 19 \\
\hline YouTube & 88 & 25 \\
\hline Instagram & 74 & 39 \\
\hline Snapchat & 59 & 54 \\
\hline Twitter & 21 & 92 \\
\hline Linkedln & 10 & 103 \\
\hline Google + & 55 & 58 \\
\hline Blogs/WordPress & 24 & 89 \\
\hline
\end{tabular}

On knowledge with MsWord, 26 students (23\%) said they knew how to do Sections, Chapter index, Figures/Tables index of figures/tables..., Manage bibliographical references, Different headers/footers and Cross-reference. However, 7 students $(6 \%)$ said they didn't know how to use any of the functionalities. Just $25 \%$ know how to use cross-reference.

TABLE 5. MSWORD, INQUIRY 1.

\begin{tabular}{|c|c|c|}
\hline On MsWord knows how to do: & Yes & No \\
\hline Sections & 67 & 46 \\
\hline Chapter index & 96 & 17 \\
\hline Figures/Tables Index... & 94 & 19 \\
\hline Managing bibliographical references & 90 & 23 \\
\hline Different headers/footers & 100 & 13 \\
\hline Cross-reference & 28 & 85 \\
\hline
\end{tabular}

On knowledge of MsExcel, 19 students (17\%) said they knew how to insert formulas/functions, using filters, creating graphics and doing ordinations. 40 Students (35\%) said they didn't know how to use any functionality.

TABLE 6. KNOWLEDGE ON MSEXCEL, INQUIRY 1.

\begin{tabular}{|c|c|c|}
\hline On MsExcel knows how to do: & Yes & No \\
\hline Insert formulas/functions & 50 & 63 \\
\hline Using filters & 26 & 87 \\
\hline Creating graphics & 69 & 44 \\
\hline Doing ordinations & 30 & 83 \\
\hline
\end{tabular}


Relatively to MsPowerPoint, 75 students (66\%) said they knew how to do temporizations, animations, using slide master and transitions. Just one student $(0.9 \%)$ said he didn't know how to use any of the items.

TABLE 7. KNOWLEDGE ON POWERPOINT, INQUIRY1.

\begin{tabular}{|c|c|c|}
\hline On MsPowerPoint knows how to do: & Yes & No \\
\hline Temporizations & 104 & 9 \\
\hline Animations & 112 & 1 \\
\hline Using slide master & 79 & 34 \\
\hline Transitions & 102 & 11 \\
\hline
\end{tabular}

46 students $(41 \%)$ said they regularly used digital libraries, Wikipedia and Google. Just one student $(0.9 \%)$ said that he didn't use any of these tools regularly.

TABLE 8. UTILIZATION OF SEARCH TOOLS AND KNOWLEDGE, INQUIRY 1.

\begin{tabular}{|c|c|c|}
\hline Uses regularly: & Yes & No \\
\hline Digital libraries & 78 & 35 \\
\hline Wikipedia & 82 & 31 \\
\hline Google & 112 & 1 \\
\hline
\end{tabular}

For 30 students $(27 \%)$, the Web usually serves social networks, newspapers, digital libraries, games and e-mail. All students said they used e-mail.

TABLE 9. UTILITY OF WEB, INQUIRY 1.

\begin{tabular}{|c|c|c|}
\hline $\begin{array}{c}\text { Usually the web servers } \\
\text { for: }\end{array}$ & Yes & No \\
\hline $\begin{array}{c}\text { Social networks } \\
\text { Newspapers }\end{array}$ & 102 & 11 \\
\hline Digital libraries & 81 & 32 \\
\hline Games & 62 & 51 \\
\hline E-mail & 113 & 50 \\
\hline
\end{tabular}

On equipment possession, $13(12 \%)$ said they had 3G, 4G, PS4 (or similar), laptop, tablet and smartphone. 5 students (4\%) don't have a laptop.

\section{TABLE 10. EQUIPEMENT POSSESSION, INQUIRY 1}

\begin{tabular}{|c|c|c|}
\hline Has: & Yes & No \\
\hline 3G & 75 & 38 \\
\hline $4 G$ & 55 & 58 \\
\hline PS4 (or similar) & 43 & 70 \\
\hline Laptop & 108 & 5 \\
\hline Tablet & 81 & 32 \\
\hline Smartphone & 94 & 19 \\
\hline
\end{tabular}

When asked to classify their motivation for learning on Information Technologies, being the scale from 1 (nothing) to 5 (much), we obtained average of $3.94,33$ students $(29 \%)$ answering that they felt really motivated and 2 not motivated.

TABLE 11. MOTIVATION FOR LEARNING ON ITS, INQUIRY 1.

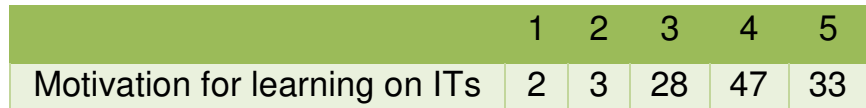

66 students didn't-t have any technology related discipline high school, being that the ones who had, had IAP (IT Applications) on 12th grade, TIC on 7th grade to 9th grade, TIC on the grade and TIC on 10th grade. 
TABLE 12. FREQUENCY OF ITS DISCIPLINES IN HIGH SCHOOL, INQUÉIRY 1.

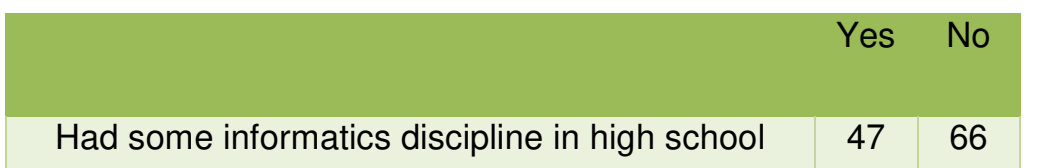

TABLE 13. DISCIPLINES FREQUENTED IN HIGH SCHOOL, INQUIRY 1

\begin{tabular}{|c|c|}
\hline If yes: which disciplines did you have? In which grades? \\
\hline IAP (IT Applications) on 12th grade & 12 \\
\hline TIC, on 7th grade to 9th grade & 8 \\
\hline TIC on 9th grade & 25 \\
\hline TIC on 10th grade & 2 \\
\hline
\end{tabular}

We obtained many kinds of answers to the question "If yes: were those disciplines useful? How?" Noting that 4 students answered that those disciplines hadn't been useful: I acquired knowledge on technologies that I didn't know.; Helped to master works that are now useful on the realization of works; Helped me to use in a better way Word, PowerPoint, etc.; Helped me to know better the functionalities of computer.; Helped me to work better on Word and on Power Point; Helped to know how to function with. Informatics programs; Learned how to create websites, how to utilize all the tools from Windows Office and many tools of edition and; video and sound production, like Adobe Premiere and Sony Vegas; Learned all the tools from Microsoft Office, among others; Understand better Word and PowerPoint.; In way to strengthen my knowledges and IT dexterity; This discipline was useful for the learning on IT and program level; Were useful helped me strengthen my knowledge on the IT world; Were useful because we strengthened our technological dexterity; were useful to learn how to work with Word; Were useful because they gave us our first notions for the country with the new technologies.; Were useful since I learned how to work with programs which were unknown to me; In IT Applications the themes weren't very deepened. So, the knowledge and learnings gotten from this discipline was vague. No; No; I didn't think it was useful, I just learned how to work with Photoshop and a program to make programs; For learning; Yes; yes; yes, in a way that I could understand better the functioning of Excel , of Word and of PowerPoint; Yes, I thought that it was really useful; Yes, they were useful, in many ways.; YES, THEY HELP THE STUDENT HAVE SOME BACKGROUNDS IN INFORMATICS; WHICH WILL BECOME USEFUL THROUGH TIME; Yes, learning principally how to use Excel; Yes, but only to work with Word and PowerPoint; Yes, to learn how to work on Excel, Prezi, and various IT programs.; Yes, for PowerPoint and some Word functionalities; Yes, for us to know more about applications and on creating programs; Yes, because I learned some techniques to use on Word and on PowerPoint; Yes, because they allowed me to acquire some basic knowledge on video, photo and sound edition.; Yes. It contributed for the enlargement of our skills. Yes. By teaching, at least, the most basic things! Helping to work with more dexterity with technology; yes. I learned how to use Office better; Honestly, I didn't know anything new in the discipline, I just desinvolved what I knew a little; knowledge; working with software, such as Excel, Word, PowerPoint.

\section{FINAL INQUIRY}

To the final inquiry answered 56 students, all from the course of Law. Three answers were taken away, from students born in 1971, 1981 and 1986 since we intended to study the generation born in the 90's. About the birth years: 11 students were born in 1994, 15 students in 1995 and other 17 in 1996. The average was near 20 years. About the genders, 37 were feminine and 16 masculine.

TABLE 14. BIRTH YEAR, INQUIRY 2.

\begin{tabular}{|c|c|c|}
\hline Birth Year & № & $\%$ \\
\hline 1990 & 1 & $2 \%$ \\
\hline 1992 & 2 & $4 \%$ \\
\hline 1993 & 6 & $11 \%$ \\
\hline 1994 & 11 & $21 \%$ \\
\hline 1995 & 15 & $28 \%$ \\
\hline 1996 & 17 & $32 \%$ \\
\hline 1997 & 1 & $2 \%$ \\
\hline
\end{tabular}


TABLE 15. GENDER, INQUIRY 2.

\begin{tabular}{|c|c|c|}
\hline Gender & № & $\%$ \\
\hline Feminine & 37 & $70 \%$ \\
\hline Masculine & 16 & $30 \%$ \\
\hline
\end{tabular}

About knowledge on MsOffice, and in a scale from 1 (nothing) to 4 (much), positive averages were obtained for different headers / footers, different number of pages per section, chapter index, captioning figures/tables. However, tables/figures index..., bibliographical references managing and Crossreference are associated with averages lower than 2.5. Two students answered nothing to all items and none answered. Knowing how to do these functionalities very well.

TABLE 16. MSWORD KNOWLEDGES, INQUIRY 2.

\begin{tabular}{|c|c|c|c|c|c|}
\hline On MsWord knows how to do: & 1 & 2 & 3 & 4 & Average \\
\hline Different headers/ footers & 3 & 10 & 36 & 4 & 2,77 \\
\hline Number of pages per section & 5 & 7 & 39 & 2 & 2,72 \\
\hline Chapter index & 9 & 5 & 35 & 4 & 2,64 \\
\hline Captioning figures/ tables... & 5 & 14 & 30 & 4 & 2,62 \\
\hline Figures/ tables captioning... & 8 & 18 & 25 & 2 & 2,40 \\
\hline Managing bibliographical references & 7 & 15 & 30 & 1 & 2,47 \\
\hline Cross-reference & 19 & 15 & 19 & 0 & 2,00 \\
\hline
\end{tabular}

Relatively to knowledge on MsExcel, there was just positive answer to over half of the for the creation of graphics. More than half of the students answered that they didn't know how to insert formulas/functions, using filters and doing ordinations. Just 5 students (9\%) answered being capable of using these four functionalities on MsExcel and fifteen (28\%) said not knowing how to use any.

TABLE 17. KNOWLEDGES OF MSEXCEL, INQUIRY 2.

\begin{tabular}{|c|c|c|}
\hline On MsExcel knows how to do: & Yes & No \\
\hline Inserting formulas/functions & 23 & 30 \\
\hline Using filters & 16 & 37 \\
\hline Creating graphics & 35 & 18 \\
\hline Doing ordinations & 14 & 39 \\
\hline
\end{tabular}

About MsPowerPoint knowledge, 28 students (53\%) answered that they knew how to do temporizations, animations, using the slide master and transitions and none answered no to these four items.

TABLE 18. MSPOWERPOINT KNOWLEDGES, INQUÉRITO 2.

\begin{tabular}{|c|c|c|}
\hline On MsPowerPoint knows how to do: & Yes & No \\
\hline Temporizations & 48 & 5 \\
\hline Animations & 52 & 1 \\
\hline Using slide master & 31 & 22 \\
\hline Transitions & 46 & 7 \\
\hline
\end{tabular}

On the question "Do you think you should have had lessons about Word / Prezi and other tools in the beginning of the semester?" 44 students (86\%) answered affirmatively, while 7 (14\%) answered that they didn't think it was necessary.

The answer is yes, we obtained the following answers: think we should have lessons on Word because I thinks it's an important (practical) part to realize works/reports. It would be a help for academic works. For us to use better these programs for the works for the different disciplines. Because it's important to know how to structure works properly and knowing how to do bibliographical references. Working with Word and Prezi is very useful, not only for academic and professional life but for personal life, too. Once they're the tools that we'll accompany throughout our academic and professional lives. Because they're tools necessary for our course and for our future professional; they better significantly the performance of our tools. Most students have little basis facing these tools and it would be very useful for our academic course and for our professional lives; so that my works can be bettered.; Yes, aiming to upgrade the quality of presented works.; because, for example, on word, great part of students doesn't know much more than the basics.; Without a doubt it will be very useful for future works and presentations throughout $1^{\text {st }}$ cycle degree, as well as on the job market, since today every and any company, independently from its area of action, functions "risk-free", resorting to market studies, 
business studies and niche target population studies..; Because it's a new way to evolve students' works, since you have more knowledge!; Relatively to Word, we should better the competences to resolve a work, structure-wise.; I think Prezi is a good tool to create a more diversified work.; I believe that other tools that might be considered interesting and functional for the realization of the course and for the future might be considered and advantage.; I think Word's an important tool for professional life and it's important to know how to use it well; In the technological world where we live is getting more and more important to work with technology and tools like Prezi are being used more my companies. In my opinion, it would help the students to better their techniques relative to those two programs, so that you can learn how to use them in the best way possible in the future, so that you contribute to future technology.; Because I never learned how to use Prezi; I think that my knowledge about all the faces of Microsoft Office could be more evolved. I think it's fundamental for my academic and professional life; Yes, to better my presentation; I think that, as Law students, were missing the Word part, etc....; Important in a nearby future. To obtain more knowledges. To obtain more knowledges. It's a way to better the SIC works, as well as in other disciplines.

\section{CONCLUSION OF THE TWO INQUIRIES}

As for fondness and interest, as for technological dexterity, the scale being 1 (nothing) to 5 (much), the average got near 4 , which reveals that students are interested and want to use technology. The 5 students who answered 1 or 2 to fondness and to interest for technology were from the feminine gender, only 1 element of the masculine gender answering 1 to the technological dexterity item, as for 10 elements of the feminine gender replied with level 2. Two of the students who answered 1 or 2 to the item of technological dexterity had a discipline of technology in high school.

There's a great usage of tools such as Facebook (87\%), Gmail (83\%), YouTube (78\%), Instagram (65\%) and Snapchat $(62 \%)$.

Relatively to MsWord, the percentage of students who say that they know how to use the functionalities is similar in both inquiries:

TABLE 19. KNOWLEDGES ON MSWORD IN BOTH INQUIRIES.

\begin{tabular}{|c|c|c|}
\hline On MsWord you know how to do: & Yes 1st Inq & $\begin{array}{c}\text { Yes 2nd } \\
\text { Inq }\end{array}$ \\
\hline Sections & $59 \%$ & $77 \%$ \\
\hline Chapter index & $85 \%$ & $74 \%$ \\
\hline Figures/ tables index & $83 \%$ & $51 \%$ \\
\hline Managing bibliographical references & $80 \%$ & $58 \%$ \\
\hline Different headers/footers & $88 \%$ & $75 \%$ \\
\hline Cross-reference & $25 \%$ & $36 \%$ \\
\hline
\end{tabular}

On behalf of curiosity, it's verified that of the 41 students who answered to both inquiries there's a little difference when talking about MsWord knowledge, verifying that 22 students who said that they knew how to use Cross-reference passed to say that they did not, while 6 students who initially had affirmed that they didn't know how to use sections, on the second inquiry said they didn't.

TABLE 20. CORSSING OF ANSWERS ABOUT MSWORD, 41 STUDENTS

\begin{tabular}{|c|c|c|c|c|}
\hline On MsWord you know how to: & $\begin{array}{c}\text { Yes } \\
\text { Yes }\end{array}$ & $\begin{array}{c}\text { Yes- } \\
\text { No }\end{array}$ & $\begin{array}{c}\text { No } \\
\text { Yes }\end{array}$ & $\begin{array}{c}\text { No } \\
\text { No }\end{array}$ \\
\hline Different headers/footers & $66 \%$ & $24 \%$ & $5 \%$ & $5 \%$ \\
\hline Sections & $59 \%$ & $10 \%$ & $15 \%$ & $17 \%$ \\
\hline Chapters index & $71 \%$ & $20 \%$ & $2 \%$ & $7 \%$ \\
\hline Figures/ Tables index... & $51 \%$ & $37 \%$ & $0 \%$ & $12 \%$ \\
\hline Managing bibliographical references & $54 \%$ & $27 \%$ & $7 \%$ & $12 \%$ \\
\hline Cross-reference & $37 \%$ & $54 \%$ & $2 \%$ & $7 \%$ \\
\hline
\end{tabular}

The answers about the knowledge of MsExcel were very similar in both inquiries, which doesn't admire us since the work meanwhile realized could not have any contact with MsExcel. 
TABLE 21. KNOWLEDGES OF MSEXCEL IN BOTH INQUIRIES.

\begin{tabular}{|c|c|c|}
\hline On MsExcel you know how to do: & Yes 1st & Yes 2nd \\
\hline Insert formulas/functions & $44 \%$ & $43 \%$ \\
\hline Using filters & $23 \%$ & $30 \%$ \\
\hline Creating graphics & $61 \%$ & $66 \%$ \\
\hline Doing ordinations & $27 \%$ & $26 \%$ \\
\hline
\end{tabular}

There's no significate answer changes in the group of students who answered both inquiries: just 6 just students start saying that they know how to use filters.

TABLE 22. CROSSING OF ANSWERS ABOUT MSEXCEL, 41 STUDENTS

\begin{tabular}{|c|c|c|c|c|}
\hline On MsExcel you know how to & Yes & Yes & No & No \\
\hline do: & Yes & No & Yes & No \\
\hline Insert formulas/functions & $34 \%$ & $5 \%$ & $12 \%$ & $49 \%$ \\
\hline Using filters & $10 \%$ & $7 \%$ & $15 \%$ & $68 \%$ \\
\hline Create graphics & $59 \%$ & $7 \%$ & $7 \%$ & $27 \%$ \\
\hline Doing ordinations & $15 \%$ & $10 \%$ & $10 \%$ & $66 \%$ \\
\hline
\end{tabular}

Relatively to MsPowerPoint, no significate differences to the answers of both inquiries are found:

TABLE 23. KNOWLEDGE OF MSPOWERPOINT IN BOTH INQUIRIES.

\begin{tabular}{|c|c|c|}
\hline On MsPowerPoint you know how to do: & Yes 1 & Yes $2^{\circ}$ \\
\hline Temporizations & $92 \%$ & $91 \%$ \\
\hline Animations & $99 \%$ & $98 \%$ \\
\hline Using slide master & $70 \%$ & $58 \%$ \\
\hline Transitions & $90 \%$ & $87 \%$ \\
\hline
\end{tabular}

There's no significate change of answers relatively to the students who answered to both inquiries: just 7 students started saying that they didn't know how to use slide master.

TABLE 24. CROSSING OF ANSWERS ABOUT MSPOWERPOINT, 41 STUDENTS.

\begin{tabular}{|c|c|c|c|c|c|}
\hline On MsPowerPoint you know how to do: & Yes- & Yes- & No- & No- \\
\hline Temporizations & Yes & No & Yes & No \\
\hline Animations & $88 \%$ & $5 \%$ & $5 \%$ & $2 \%$ \\
\hline Using slide master & $98 \%$ & $2 \%$ & $0 \%$ & $0 \%$ \\
\hline Transitions & $59 \%$ & $17 \%$ & $10 \%$ & $15 \%$ \\
\hline
\end{tabular}

We don't find relation between having had a technology discipline in high school and the three tools of MsOffice in question. We didn't find a relation between possessions of equipment with that knowledge, either.

\section{FINAL CONCLUSIONS}

With this article we can verify that the students of the course of Law of 2014-2015 who responded to the inquiries have, generally, fondness, interest and technological dexterity. An average of 3.9 points in 5 about the motivation for the use of technology was obtained. That the most part of the students who answered have an account on Facebook (87\%), Gmail (83\%), YouTube (78\%), Instagram (65\%), and Snapchat (62\%). That on the tools of MsOffice students still show some adversities. On MsWord, creating and using sections and utilizing cross-reference. After the work presentation, a large part of the student basis changed some of their answers when questioned about MsWord. The questioned students have very little knowledge about MsExcel, knowing only how to create graphics, while most don't know formulas/functions, filters and ordinations. The students said they knew how to use MsPowerPoint, although many of them didn't know use slide master. $96 \%$ of students have their own laptop, all have email and only 1 student said he didn't use Google. 58\% of students didn't have any technological discipline in high school. In the end of the semester, the question "Do you think you should have had lessons about Word / Prezi and other tools in the beginning of the semester?" 44 students (86\%) answers yes. 
It can clearly be understood that the young people from the Generation Z join College with a lot of usage of technologies, but with little knowledge of MsOffice. Is it needed to offer these competences to students so that they can do their academic work and to know how to use them in future working life?

\section{REFERENCES}

[1] Prensky, Marc, "Digital Natives, Digital Immigrants." On The Horizon 9.5: n. page., 2001.

[2] Schmidt, Lucinda, and Peter Hawkins. "Children of the Tech Revolution."Life \& Style., 2008. 